IZA DP No. 7516

Giving and Sorting among Friends:

Evidence from a Lab-in-the-Field Experiment

Christine Binzel

Dietmar Fehr

July 2013 


\title{
Giving and Sorting among Friends: Evidence from a Lab-in-the-Field Experiment
}

\author{
Christine Binzel \\ Heidelberg University \\ and IZA
}

Dietmar Fehr

$W Z B$

\author{
Discussion Paper No. 7516 \\ July 2013
}

\author{
IZA \\ P.O. Box 7240 \\ 53072 Bonn \\ Germany \\ Phone: +49-228-3894-0 \\ Fax: +49-228-3894-180 \\ E-mail: iza@iza.org
}

\begin{abstract}
Any opinions expressed here are those of the author(s) and not those of IZA. Research published in this series may include views on policy, but the institute itself takes no institutional policy positions. The IZA research network is committed to the IZA Guiding Principles of Research Integrity.

The Institute for the Study of Labor (IZA) in Bonn is a local and virtual international research center and a place of communication between science, politics and business. IZA is an independent nonprofit organization supported by Deutsche Post Foundation. The center is associated with the University of Bonn and offers a stimulating research environment through its international network, workshops and conferences, data service, project support, research visits and doctoral program. IZA engages in (i) original and internationally competitive research in all fields of labor economics, (ii) development of policy concepts, and (iii) dissemination of research results and concepts to the interested public.
\end{abstract}

IZA Discussion Papers often represent preliminary work and are circulated to encourage discussion. Citation of such a paper should account for its provisional character. A revised version may be available directly from the author. 


\title{
ABSTRACT \\ Giving and Sorting among Friends: Evidence from a Lab-in-the-Field Experiment
}

\begin{abstract}
Among residents of an informal housing area in Cairo, we examine how dictator giving varies by the social distance between subjects - friend versus stranger - and by the anonymity of the dictator. While giving to strangers is high under anonymity, we find - consistent with Leider et al. (2009) - that (i) a decrease in social distance increases giving, (ii) giving to a stranger and to a friend is positively correlated, and (iii) more altruistic dictators increase their giving less under non-anonymity than less altruistic dictators. However, friends are not alike in their altruistic preferences, suggesting that an individual's intrinsic preferences may not necessarily be shaped by his (or her) peers. Instead, reciprocal motives seem important, indicating that social relationships may be valued differently when individuals are financially dependent on them.
\end{abstract}

JEL Classification: C93, D64, L14, O12

Keywords: giving, reciprocity, social distance, networks, sorting

Corresponding author:

Christine Binzel

Department of Economics

Heidelberg University

Bergheimer Str. 58

69115 Heidelberg

E-mail: christine.binzel@awi.uni-heidelberg.de

\footnotetext{
* We are indebted to the Participatory Development Program in Urban Areas of the German Agency for International Cooperation (GIZ) in Cairo, in particular to its staff at the local office in Manshiet Nasser and to our research assistants from Cairo University. We also thank Christoph Vanberg and an anonymous referee for valuable comments. Financial support from DIW Berlin, the Economic Research Forum (ERF) and the German Research Foundation (DFG) through SFB 649 "Economic Risk" is gratefully acknowledged.
} 


\section{Introduction}

There has been growing interest in the experimental literature in understanding the determinants of prosocial behavior among socially close persons, such as direct friends and friends of friends as opposed to strangers, and how real-world social networks evolve (e.g. Leider et al., 2009; BrañasGarza et al., 2010; Goeree et al., 2010). Prosocial behavior among socially close persons is pervasive in both developing and developed countries. However, empirically it is difficult to distinguish whether such behavior is driven by preferences or by the expectation of future transactions. In one of the first studies addressing this issue, Leider et al. (2009) examine prosocial giving among Harvard undergraduates and their peers (students living in the same dormitory). By varying both the social distance between peers and the anonymity of the dictator, they are able to discriminate between these different motives of giving.

In this paper, we report the results from a lab-in-the-field experiment that we conducted in an informal housing area in Cairo. As part of this experiment, we collected data from several dictator games which are, in parts, similar to the dictator games of Leider et al. (2009), henceforth LMRD, allowing us to compare our results to their main findings. ${ }^{1}$ For several reasons we may expect differences in sharing behavior across these two settings. First, in developing countries social networks often substitute for weak or missing formal institutions. Hence, people are financially much more dependent on their social network (Munshi, 2006). ${ }^{2}$ This may have consequences, in turn, on the sorting among friends, as expectations about future transactions may play a more important role than intrinsic values. Second, and relatedly, results from standard dictator games indicate that transfers are comparatively high among non-student subject pools in developing countries (e.g. Cardenas and Carpenter, 2008). We may therefore expect social distance to have a smaller effect on dictator giving in our sample.

\section{Experimental design and procedure}

The experiment took place at a cultural theater in Manshiet Nasser, an informal housing area in Cairo. ${ }^{3}$ Invited residents were required to participate together with a friend. In total, we con-

\footnotetext{
${ }^{1}$ In Binzel and Fehr (2013) we examine how the social distance between players affects behavior in a binary trust game with hidden action. We use respondents' behavior in one of the two dictator games to control for other-regarding preferences, but do not analyze the data from the dictator games itself.

${ }^{2}$ For the importance of social networks in Cairo see, for example, Singerman (1995); Hoodfar (1997).

${ }^{3}$ See Online Appendix for details on the experimental procedures and for participant characteristics.
} 
ducted five sessions with 144 participants (72 pairs). After playing a binary trust game with hidden action (for details see Binzel and Fehr, 2013), participants played several variants of the dictator game, in which they were asked to allocate an endowment of 20 Egyptian Pound (L.E.) between themselves and another participant. ${ }^{4}$

We used a two-by-two design inspired by LMRD. First, the identity of dictators either remained anonymous (as in the standard dictator game) or was revealed at the end of the session (anonymous/non-anonymous treatment). We refer to the difference in the amount given in these two treatments as non-anonymity effect. Second, in each treatment dictators were asked to make an allocation decision once for being paired with their friend (friend pairing) and once for being paired with a randomly chosen workshop participant (stranger pairing). We refer to the difference in the amount given to the friend versus a stranger as social distance effect. ${ }^{5}$ Participants were paid for one of the two decisions (stranger or friend) in each treatment (anonymous / non-anonymous). ${ }^{6}$

In the non-anonymous treatment, we additionally collected the participants' beliefs. That is, after participants made their allocation decisions for the friend and the stranger pairing, we asked them what they expected to receive both from a stranger and from their friend.

We deviate from LMRD, and from the standard dictator game, in that we introduced role uncertainty in order to elicit other-regarding preferences for all study participants. That is, in each treatment (anonymous/non-anonymous) all participants were required to make an allocation to their friend and a stranger, and only at the end of the session we selected their role (dictator or recipient). While this may lead to higher transfers than in a standard dictator game, the observed transfers in the anonymous/stranger treatment compare well with other standard dictator game studies that have been conducted with a non-student subject pool in developing countries (see e.g., Cardenas and Carpenter, 2008).

Closely related to LMRD and to our study is a recent lab-in-the-field experiment by Ligon and Schechter (2012). Ligon and Schechter (2012) developed their design independently of LMRD

\footnotetext{
${ }^{4}$ At the time of the study, 20 L.E. was more than a worker's daily wage (about 10 to 15 L.E.). Endowments of this size are common for lab-in-the-field experiments conducted in developing countries.

${ }^{5}$ Following Jackson (2008), we define social distance as the path length between trading partners in social networks. Accordingly, we compare allocation decisions among direct friends (social distance of 1) to allocation decisions among strangers (infinite social distance). Note that in LMRD participants had to make allocation decisions for a range of social distances. We compare our stranger pairing to pairings of social distance 4 in LMRD, which is the largest social distance involving a recipient whose identity is revealed in their non-anonymous treatment and which has a sufficiently large $N$. A social distance of 4 is larger than the expected social distance of a randomly chosen student in their sample, which is a friend of a friend of a friend (social distance of 3 ).

${ }^{6}$ In the anonymous treatment, we did not reveal which pairing was chosen for payment in order to ensure decision makers' anonymity. Note that we randomized the order of the anonymous and the non-anonymous treatments as well as the order of the pairings (stranger versus friend).
} 
Table 1: Aggregate results by pairing and treatment.

\begin{tabular}{llcc}
\hline \hline & & \multicolumn{2}{c}{ Anonymity of the dictator } \\
& & anonymous & non-anonymous \\
\hline \multirow{3}{*}{ Social distance } & \multirow{2}{*}{ stranger } & $7.29(3.55)$ & $7.90(3.10)$ \\
& & {$[36.42 \%]$} & {$[39.48 \%]$} \\
& \multirow{2}{*}{ friend } & $8.85(3.12)$ & $9.21(2.60)$ \\
& & {$[44.27 \%]$} & {$[46.04 \%]$} \\
\hline
\end{tabular}

Notes: Average transfers to the friend/stranger in each treatment (out of 20 L.E.) are reported with standard deviations in parentheses. The corresponding percentages are reported in brackets. $N=144$ (72 pairs).

and examine motives of sharing among households, rather than individuals, in rural Paraguay. While they also vary the anonymity of the dictator, they additionally vary - in contrast to LMRD and to our study - whether or not the dictator can choose the recipient household. Therefore, in cases where dictators can choose the recipient, their motives for sharing are likely interdependent with their choice of a recipient. ${ }^{7}$

\section{Experimental results}

\subsection{Dictator transfers by pairing and treatment}

Table 1 presents the aggregate results by treatment (anonymous / non-anonymous and stranger/friend). On average, dictators transfer $36.42 \%$ of their endowment to a stranger under anonymity. Transfers increase when moving from anonymity to non-anonymity and from being paired with a stranger to being paired with a friend, leading to an average transfer in the friend/non-anonymous treatment of $46.04 \%$ of the endowment. At the same time, the variance of the transfer decreases: it is highest in the stranger / anonymous treatment and smallest in the friend/non-anonymous treatment. These figures suggest that a significant share of dictators splits the endowment. This is indeed the case, in particular in the friend pairing: $70.8 \%$ of dictators share their endowment equally with their friend in the anonymous treatment and $79.2 \%$ of dictators do so in the non-anonymous treatment. $^{8}$

\footnotetext{
${ }^{7}$ Several recent experimental studies in developing countries also utilize participants' real-world social relationships. They examine, amongst others, how giving varies across different types of networks (D'Exelle and Riedl, 2010), sharing among spouses (Bezu and Holden, 2013) as well as third-party punishment and trust (e.g., Vollan, 2011; Breza, Chandrasekhar and Larreguy, 2013).

${ }^{8}$ The corresponding shares in the stranger pairing are $50.7 \%$ and $53.5 \%$.
} 
Table 2: Regression results for each treatment.

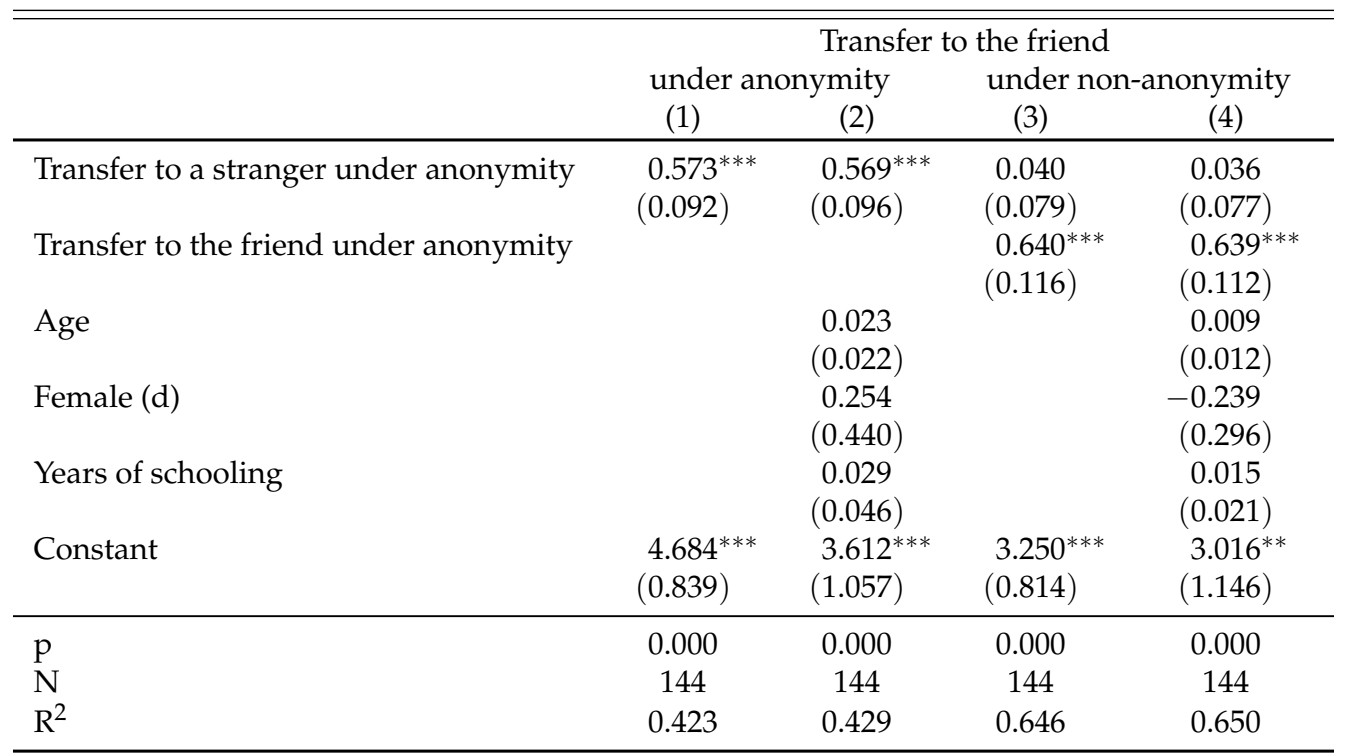

${ }^{*} p<0.10,{ }^{* *} p<0.05,{ }^{* * *} p<0.01$. (d) Dummy variable.

Notes: OLS estimation results are reported with robust standard errors accounting for clustering at the friend pair level in parentheses. Transfers are in Egyptian Pound (L.E.).

The corresponding dictator transfers reported in LMRD for Harvard undergraduates are: $17.58 \%$ (stranger/anonymous) 23.92\% (friend/anonymous), 24.32\% (stranger/non-anonymous), and $32.66 \%$ (friend/non-anonymous). ${ }^{9}$ Not surprisingly, given the much higher levels of giving among Cairene residents as compared to Harvard undergraduates, the increase in giving when social distance is reduced is in our study smaller in relative terms: transfers increase on average by $22 \%$ under anonymity and by $17 \%$ under non-anonymity. ${ }^{10}$

In the following, we examine the effect of social distance at the individual level and by treatment. Columns (1) and (2) in Table 2 show results from regressing a dictator's transfer to the friend on her transfer to a stranger under anonymity, both with and without individual controls. The results indicate that under anonymity transfers to the friend and to a stranger are significantly positively correlated. A 1 L.E. increase in the transfer to a stranger is associated with, on average, a 0.57 L.E. increase in the transfer to the friend. Age, gender, and education do not predict dictator

\footnotetext{
${ }^{9}$ As mentioned in section 2, we refer to a "stranger" in LMRD to recipients with a social distance of 4 . Percentages are calculated from the mean transfers reported in Table 2 (p. 1830) for the dictator game with exchange rate 1:1.

${ }^{10}$ In LMRD, transfers increase by $36 \%(34 \%)$ in the anonymous (non-anonymous) treatment following a reduction in social distance. Note that we do not observe that the social distance effect differs significantly across treatments, which is consistent with "Result 3" in LMRD stating that the social distance effect is larger for friends than for strangers only when giving is efficient. Corresponding regression results accounting for clustering at the friend pair level are available upon request.
} 
Table 3: Correlation in transfers among friends.

\begin{tabular}{|c|c|c|c|}
\hline & \multicolumn{2}{|c|}{ Anonymity of the dictator } \\
\hline & & anonymous & non-anonymous \\
\hline \multirow{2}{*}{ Social distance } & stranger & $0.0859(0.4729)$ & $0.1246(0.2969)$ \\
\hline & friend & $0.1260(0.2917)$ & $0.1675(0.1596)$ \\
\hline
\end{tabular}

giving, which corroborates other studies (e.g. D'Exelle and Riedl, 2010; Goeree et al., 2010).

Columns (3) and (4) in Table 2 examine dictators' transfer to the friend under non-anonymity. By controlling for a dictator's transfer to a stranger under anonymity, which LMRD refer to as "baseline altruism", the coefficient estimate on the transfer to the friend under anonymity captures the relationship between an additional amount transferred to the friend (relative to a stranger) under anonymity and the transfer to her friend under non-anonymity. The fact that the coefficient estimate is less than 1 hence implies that the additional transfer made to a friend under anonymity and the non-anonymity effect are substitutes. Altruistic individuals thus respond less to extrinsic motives (or, incentives) than selfish ones.

Both the finding that giving to strangers and to friends is positively correlated and the finding that more altruistic dictators increase their giving less under non-anonymity than less altruistic dictators are consistent with the results reported in LMRD. ${ }^{11}$

\subsection{Sorting among friends}

An important question in the social network literature is how social networks form and, relatedly, whether friends share certain preferences. LMRD report that friends sort by baseline altruism, i.e. a subject's and her friends' transfer to a stranger under anonymity are positively correlated. ${ }^{12}$ Contrary to their finding, we do not find any evidence that friends sort by baseline altruism. Correlating transfers within each friend pair for each of the four treatments, we find a weak and statistically insignificant correlation between the baseline altruism of friends (see Table 3). Instead, the correlation is strongest for the friend/non-anonymous treatment (albeit still insignificant). Given the crucial role social networks play for the poor, such as providing access to goods and

\footnotetext{
${ }^{11}$ See "Result 1" and "Result 5" in LMRD.

${ }^{12}$ See "Result 6" in LMRD. Note that LMRD could draw on multiple friends per subject.
} 
services, mutual insurance and informal contract enforcement (e.g. Fafchamps, 1992; Foster and Rosenzweig, 2001; Cox and Fafchamps, 2008), it may not be too surprising that friends are alike in terms of their reciprocity. To this speaks the fact that in the non-anonymous treatment a dictator's belief about his or her friend's transfer, i.e. the expected reciprocity of the friend, is significantly correlated with his (or her) transfer to the friend (Spearman's $\rho=0.5119, p<0.01, N=144$ ). ${ }^{13,14}$

Leider et al. (2010) find - drawing on the same sample of Harvard undergraduate students as in LMRD - that while friends sort by baseline altruism, students have difficulties in predicting their friend's baseline altruism. They interpret this as providing suggestive evidence that sorting by baseline altruism is not a selection effect (more altruistic individuals choose to have more altruistic friends), but a treatment effect ("our friends shape our social preferences") (Leider et al., 2010, p. 137). In our study, friend pairs have known each other for 8 years on average and the majority meets each other on a daily basis. The fact that baseline altruism is not strongly correlated within friend pairs thus suggests that a treatment effect is unlikely. It also suggests, together with the previous result that individuals' own reciprocity is significantly correlated with the reciprocity they expect from their friend, that individuals may choose their friends differently in different contexts.

\section{Conclusion}

We report findings from several dictator games that we conducted among residents of an informal housing area in Cairo. Despite drawing on very different subject pools and despite (small) differences in the experimental design, we observe that changes in the social distance between the dictator and the recipient and in the anonymity of the dictator produce similar behavioral responses as those reported in LMRD. In particular, we also find that more altruistic dictators respond less to extrinsic motives - i.e. to changes in the anonymity of the dictator - than less altruistic ones.

In contrast to LMRD, however, we find evidence that friends in our sample sort differently than Harvard undergraduates. Contrary to Harvard undergraduates, altruistic individuals in our sample are not more likely to be paired with an altruistic friend than are selfish individuals. As friend pairs in our sample have known each other for several years and meet each other frequently,

\footnotetext{
${ }^{13}$ Subjects' belief about their friend's transfer is also significantly correlated with their friend's actual transfer (Spearman's $\rho=0.2596, p<0.01, N=144)$.

${ }^{14}$ The possibility to earn money in the experiment may have influenced the selection of friends. Note, however, that participants had no prior information on the tasks in the experiment and that we do not find differences in giving between invited residents and their friends.
} 
this suggests that friends may not necessarily shape our intrinsic preferences as hypothesized in Leider et al. (2010). Moreover, given the important role social networks play for the poor, our results may indicate that the poor do not have the luxury to choose their friends as freely as they may wish. Or, friendships may be valued differently - with (expected) reciprocity being important, rather than intrinsic values per se - when individuals are more dependent on them in their everyday life.

\section{References}

Bezu, Sosina, and Stein Holden. 2013. "Generosity and social distance in dictator game field experiments with and without a face." Centre for Land Tenure Studies Working Paper 01/13.

Binzel, Christine, and Dietmar Fehr. 2013. "Social distance and trust: experimental evidence from a slum in Cairo." Journal of Development Economics, 103: 99-106.

Brañas-Garza, Pablo, Ramón Cobo-Reyes, María Paz Espinosa, Natalia Jiménez, Jaromir Kovarik, and Giovanni Ponti. 2010. "Altruism and social integration." Games and Economic Behavior, 69(2): $249-257$.

Breza, Emily, Arun G. Chandrasekhar, and Horacio Larreguy. 2013. "Mobilizing investment through social networks: evidence from a lab experiment in the field." mimeo.

Cardenas, Juan Camilo, and Jeffrey Carpenter. 2008. "Behavioural development economics: lessons from field labs in the developing world." Journal of Development Studies, 44(3): 311-338.

Cox, Donald, and Marcel Fafchamps. 2008. "Extended Family and Kinship Networks: Economic Insights and Evolutionary Directions." In Handbook of Development Economics. Vol. 4, , ed. Paul T. Schultz and John A. Strauss, Chapter 58, 3711-3784. Elsevier.

D’Exelle, Ben, and Arno Riedl. 2010. “Directed generosity and network formation: network dimension matters." IZA Discussion Paper 5356.

Fafchamps, Marcel. 1992. "Solidarity Networks in Preindustrial Societies: Rational Peasants with a Moral Economy." Economic Development and Cultural Change, 41(1): 147-174. 
Foster, Andrew D., and Mark R. Rosenzweig. 2001. "Imperfect Commitment, Altruism, and the Family: Evidence from Transfer Behavior in Low-Income Rural Areas." Review of Economics and Statistics, 83(3): 389-407.

Goeree, Jacob, Margaret Mcconnell, Tiffany Mitchell, Tracey Tromp, and Leeat Yariv. 2010. “The 1/d law of giving." American Economic Journal: Microeconomics, 2(1): 183-203.

Hoodfar, Homa. 1997. Between Marriage and the Market - Intimate Politics and Survival in Cairo. Berkeley, CA:University of California Press.

Jackson, Matthew O. 2008. Social and Economic Networks. Princeton:Princeton University Press.

Leider, Stephen, Markus M. Möbius, Tanya Rosenblat, and Quoc-Anh Do. 2009. “Directed altruism and enforced reciprocity in social networks." Quarterly Journal of Economics, 124(4): 18151851.

Leider, Stephen, Markus M. Möbius, Tanya Rosenblat, and Quoc-Anh Do. 2010. “What do we expect from our friends?" Journal of the European Economic Association, 8(1): 120-138.

Ligon, Ethan, and Laura Schechter. 2012. "Motives for sharing in social networks." Journal of Development Economics, 99(1): 13-26.

Munshi, Kaivan. 2006. “Nonmarket Institutions." In Understanding Poverty. , ed. Abhijit Vinayak Banerjee, Roland Bénabou and Dilip Mookherjee, Chapter 26, 389-399. New York:Oxford University Press.

Singerman, Diana. 1995. Avenues of Participation: Family, Politics, and Networks in Urban Quarters of Cairo. Princeton:Princeton University Press.

Vollan, Björn. 2011. "The difference between kinship and friendship: (field-) experimental evidence on trust and punishment." The Journal of Socio-Economics, 40(1): 14-25. 